\title{
alpha
}

\section{Hiraeth, or Queering Time in Archives Otherwise}

\section{Onyeka Igwe and JD Stokely}

\begin{abstract}
Archives are the physical manifestations of our collective understanding of history, a way of proving and so legitimising the existence of cultures, practices, and peoples. However, for queer and trans people of colour (QTPOC), entrance into the archive is not easily permitted; the truths of their lives have been, and are presently, excluded, claimed as contingent and/or rendered "folk"-lesser forms of knowledge. "Hiraeth" is a Welsh word that is difficult to translate into English. It speaks of a longing or homesickness for a place that is no longer, or never was. For QTPOC, the archive is this, a hiraeth space. We use "hiraeth" to describe the liminal space in which experiences of home, media practices, and a relationship to the archive can exist. As two Black queer artists who in their work have been exploring ways to implode the archive, in this article we look at how our practices can expand what the archive holds and further provide a space to render the untranslatable, the im/possible, as archive material. It is a strategy of both redefinition and defiance.
\end{abstract}

For queer black artists, the archive can be both dangerous and disappointing. Saidiya Hartman describes archival material relating to black history as a repository of "stories that ... are not about them, but rather about the violence, excess, mendacity, and reason that seized hold of their lives [and] transformed them into commodities and corpses" (2). It can seem like an unlikely basis for fruitful and generative practices. However, time-based media, namely performance, film, and video, share an interest in the archive and its aftermath. As queer black artists working in these media we have developed an ongoing practical and pedagogical collaboration.

Two works began this collaborative enquiry and act as a foundation from which to explore how these practices operate in the world. Throughout, we have explored several theoretical frameworks, from autoethnography to hauntology. This article attempts to mimic the energy and dynamic of this particular collaboration. It begins and ends with a conversation between us about our work. The first conversation maps out the genesis of our work and the impulses behind its creation, whilst the second conversation charts the progress of our practices in an attempt to reflect upon where we both are now in relation to these concepts and ideas. Bisecting these two conversations are explorations of the key theoretical understandings that have anchored the collaborative enquiry, beginning with a discussion of archives and time, then moving on to the ways in which we attempt to transform the archive in our practices through "hiraeth" (a Welsh word which means "nostalgia", "homesickness"), autoethnography, and queering time. ${ }^{1}$ Finally, the article returns to the question of archives and the potential for their activation through timebased media. 


\section{Conversation \#1}

ONYEKA: We started this archival enquiry from a collaboration. I was helping you on your performance piece Reparations (2014) at the same time that I was researching and making my film, We Need New Names (2015). Coincidentally, both projects were about similar things: our grandmothers and how to find them, and therefore ourselves, in the archive. We Need New Names came out of the discovery of the DVD presentation of my grandmother's funeral (Fig. 1). In watching it I recognised my distance from and dissonance with the material. My gaze was ethnographic, as if watching a Jean Rouch film instead of my own grandmother's funeral. I felt the weight of diaspora and disconnection and I wanted to reflect that in a film. So, I put this familial HDV record alongside early colonial missionary $16 \mathrm{~mm}$ films and late-twentieth-century academic ethnography on VHS, as well as speculative blank space. Putting these different mediums alongside each other, I hoped, would elevate my grandmother's funeral DVD to that of ethnographic text and speak to the possible ways of addressing lack in the archive.

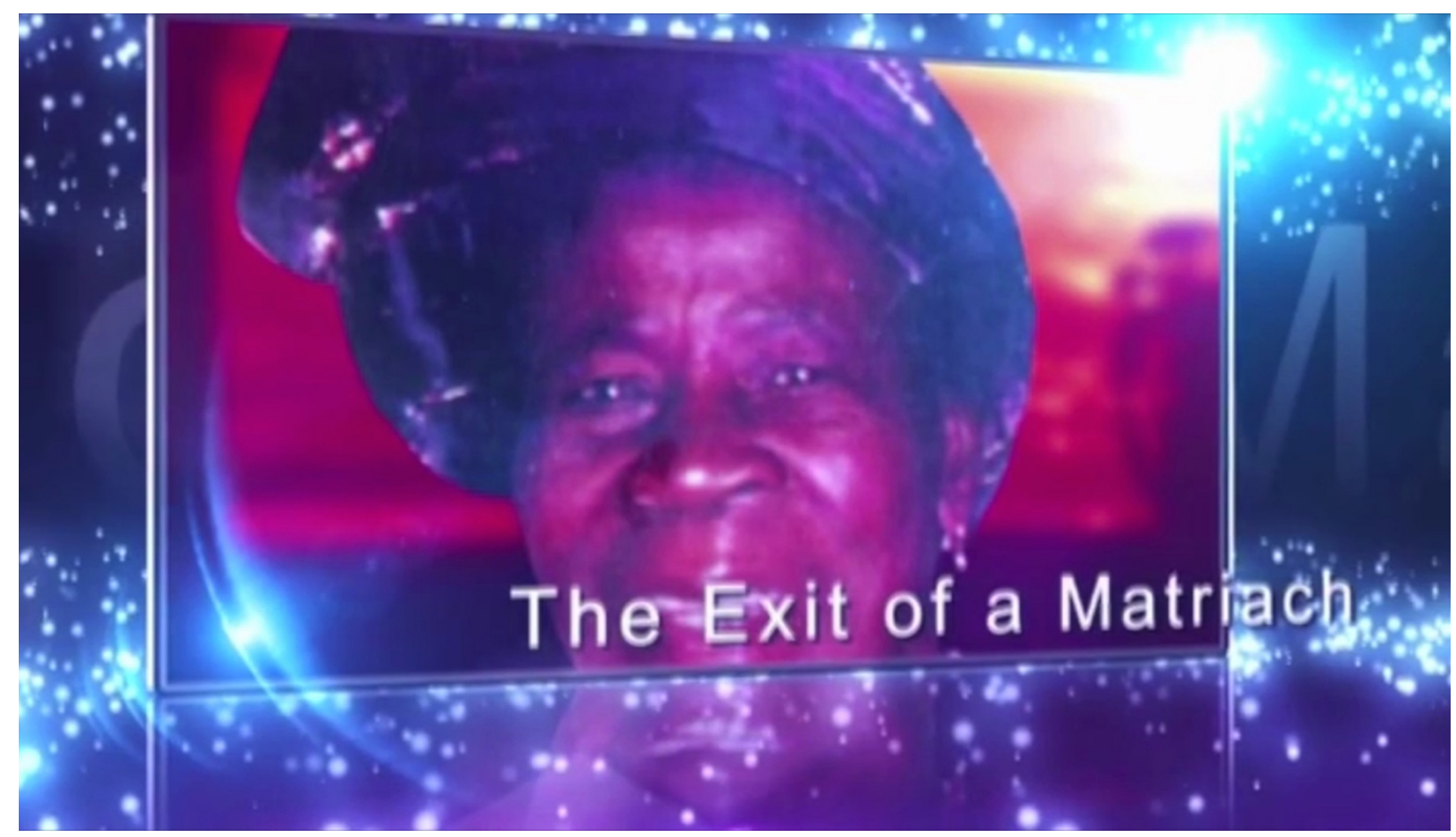

Figure 1: Still from We Need New Names (2015). Courtesy of Onyeka Igwe.

STOKELY: And while we were working together, I became interested in this idea of an impossible archive, or a fictive archive. Both of our projects used our grandmothers' stories as ways to explore the gaps in the archive, and in a way, used reimagined archival material as a critical intervention. My grandmother has been saying for years that, when my grandfather left her alone in Jamaica with their five sons to leave for the UK in the late 1950s, she often thought about following him to England to kill him. But instead, she emigrated to America. In my solo performance Reparations, my original intention was to reimagine that story with my grandmother's murder of my grandfather. I thought about this rewriting of my family history as time travel. Instead, what I created was a performative lecture that juxtaposed slides of 1950s archival images and British Pathé videos of UK tourism in Jamaica with scratchy recordings of my grandmother's patois, blank 
projection slides, and my own patchy childhood memories of Jamaica. I attempted to ask the question, "What happens to people who are left behind, and what are the consequences for those that do the leaving?" as a way of pointing a finger to blame both my grandfather and the UK for abandoning my grandmother and others like her.

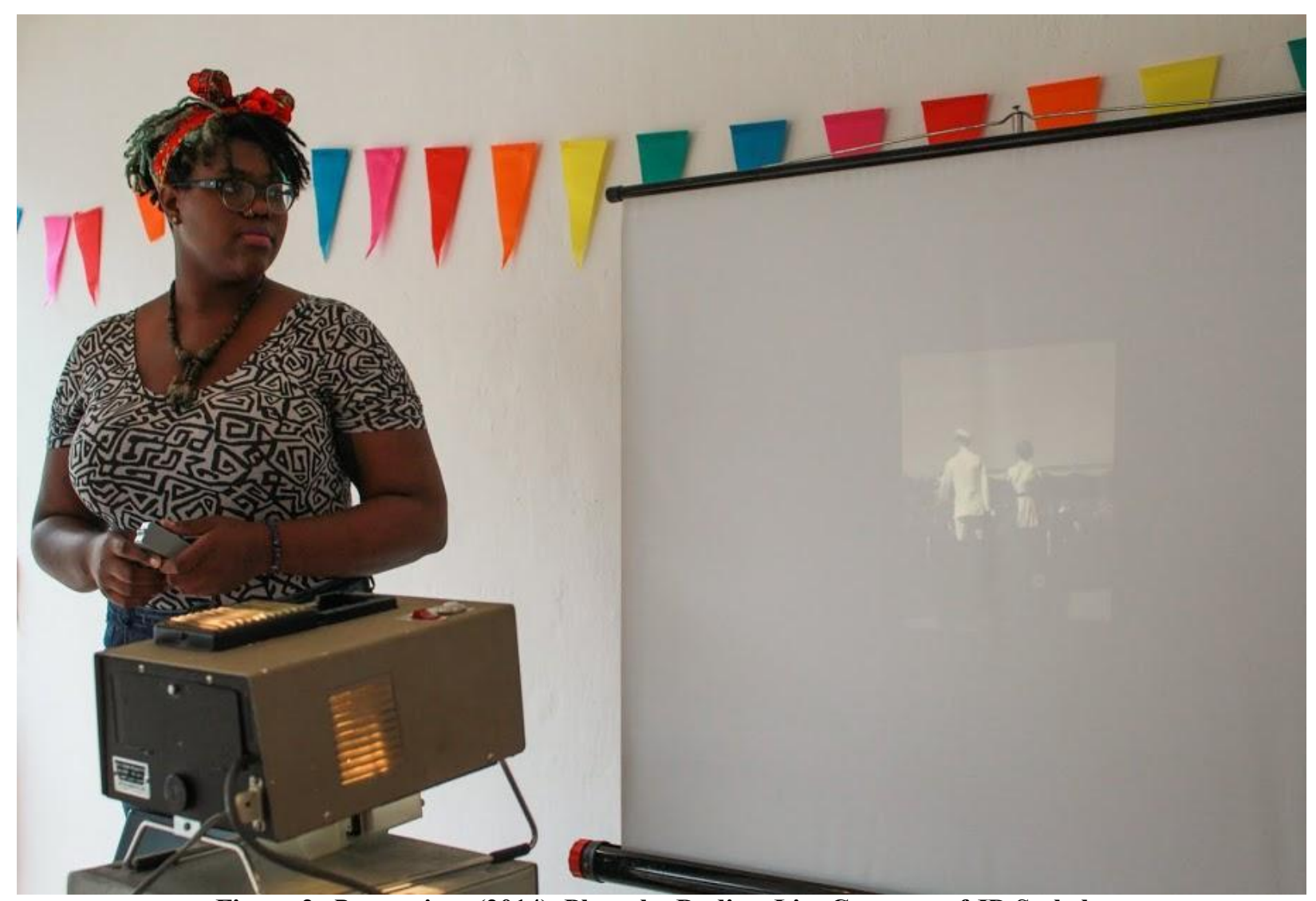

Figure 2: Reparations (2014). Photo by Dadiow Lin. Courtesy of JD Stokely.

Reparations is performed as part birthday party, part performative lecture. My set is simple, just a cassette player, a slide projector, and a screen. It is very participatory - as soon as they walk in, audience members are asked to put on birthday party hats, and I ask them a number of questions about Jamaican history and national facts. Most of the slides are blank, except for black-and-white images of the Queen touring Jamaica, so it is about creating an imaginative, fictional space with the audience. They really have to work.

When I began touring the piece, I was performing for mostly white audiences, and they thought the blank slides were really funny, mostly because I was pointing to squares of light on a wall and asking them to name what they saw. I did one performance at 198 Contemporary Arts \& Learning, a centre for visual arts in Brixton, London, which is a historically Jamaican neighbourhood (Fig. 2). For this particular performance, there were quite a lot of Jamaicans in the audience. And the piece totally changed. The Jamaican folks in the audience totally got it - they got the cultural references. When I said name that ship, they could say "Windrush". When I showed them a picture of my grandmother, they could imagine their mothers and grandmothers. I and those other Jamaicans in the room could see ourselves clearer in those squares of light than we could in 
the actual archival images we were so used to seeing. Eventually, my white audience members stopped laughing, because they realised that there was something they couldn't see, something they were being left out of. And so the keepers of knowledge changed, too.

ONYEKA: I too went looking for myself in the archive. You showed me newsreel pieces of royal tours in Jamaica, so I went looking for the royal tours that featured my own ancestors. I found an unnamed woman from Onitsha, Nigeria, dancing for Queen Elizabeth II. The British Pathé newsreel she appeared in covered the Royal Tour of Nigeria of 1956. In stadiums in Kaduna and Enugu, various groups produced displays of "native" life for the Royal inquisitors. They showed off local handicrafts, traditional cooking methods and performed "tribal" dance displays, which the Queen and the Duke of Edinburgh watched from a safe distance in the crowd. This was filmed four years before Nigerian independence and a year before my mother was born a Nigerian subject of the British Empire in a village not very far from the Enugu stadium.

The voiceover in the newsreel introduces a group of women dancing and then the frame closes in on one woman. She never looks up, so the camera lens doesn't capture her face, only her dancing body. I found myself in her stoop, bended knee and rounded arms, she beckoned me to memories of my grandmother, my mother and recollections of myself. I was startled into this connection and frozen in the moment of recognition; there was a through line that joined her to me. What if life was infinite and "grandparents never die, nor do great-grandparents, great-aunts and great-uncles, great great-aunts, and so on, back through the generations, all alive"? (Lightman 138). Watching this woman dance on my screen put me in my place in the line of others dancing stooped, eyes averted, to a silent but deeply known rhythm. I was awakened to my "blood memory" in watching this woman dance (Graham 9).

Memory of a movement that exists in "the black before and before" (Harney and Moten 17). I can't locate that in a place, because I didn't grow up in Nigeria. I don't know it, the place it exists in is inside of me. The embodied memory that is awakened in that newsreel makes me feel like the archive can connect me to something that I don't have direct experience of, that isn't landed, that exists somewhere in the space between. So, in that way the archive becomes the home that hiraeth (on which more below) is speaking of. "I am trying to think that, and say that, in as many ways as possible" in my practice (Moten, Blur xiii).

In making another work, Her Name in My Mouth (2017), I thought a lot about allowing the work to speak to different people: it was OK that some people were in the know and some people weren't. None of the Igbo words spoken in the film are translated and it is largely a film without dialogue, which allows gesture to be the central mode of communication. This was influenced by the notion that gesture is "a point of transfer for the cultural exchange of knowledge" (Bradley 21).

After making these works, we discovered this commonality was meaningful beyond the singular works we had created. It had a significance that we wished to pursue - for as much as we could not find ourselves in the archives, we still felt the need, desire or impulse to "reclaim the past" and that reclaiming had to be done on our own terms. So, a question became how could we reckon with the archive and its operation as a fossilisation of linear time? 


\section{Archives and Linear Time}

In order to consider the ways in which we have attempted to answer this question, it is necessary to set out our understanding of the archive. Archives have long been understood as collections of the past - they help us to know ourselves as societies, communities, cultures and nations. As Matthew Kurtz has written, "[i]nstitutional archives played a potent part in the construction and cementation of clearly defined (though contested) subject categories" (86). This occurs as "archivisation", a process that operates within this framework to produce knowledge (Derrida 4). Institutional archives relating to the black experience have another layer, as they are formed through the mechanism of a specific kind of knowledge production - that being the strain of Western positivism that was the cornerstone of the colonial project (Richards 4). These archives are a "product of capitalism" and part of a "European cultural project", which is motivated by a deep desire to "catalogue, and thus order, or impose a hierarchy on, the fruits of colonial theft" (Mackindral). The cataloguing, ordering and intrinsically connected imposition of hierarchy is the work of archivisation in institutions. It is where value is assigned to collections of the past, and this value adding makes it history.

The work of poststructuralists has allowed for archives to be examined as spaces where "things are collected and held that are important, relevant and valuable for a particular cultureall other unimportant, irrelevant, worthless things remain in the profane realm, beyond the archive" (Groys 178-9). In this conceptualisation, archives become sites of knowledge production, in such a way that they are "the system of discursivity that establishes the possibility of what can be said in a given society" at a particular time and in a particular geographical place (Foucault 128). The archive is a way of reproducing a certain kind of knowledge whilst simultaneously creating the hegemonic formation of how we know.

The specific archival research I (Onyeka Igwe) have undertaken since making We Need Names has involved the British Colonial Film Archive. It is made up of a variety of moving images created during the lifespan of the Colonial Film Unit: ethnographic films, films produced by the British state, films produced by industry and businesses as well as the amateur recordings produced by apparatchiks of the colonial machine: administrators, district officers, missionaries and so on who took 16mm cameras along with them on their imperial adventure. I use the Colonial Film Unit as my temporal frame (1933-1955) because it is the explicit enunciation of moving images as a particular "device for colonial administration" ("Colonial"). This is the moment the British state identifies moving images as capable of doing the work of the colonial project. And so, this is an archive that contains and promotes colonial fantasies of blackness that sustained and sustain racial regimes of power.

In this way, institutional colonial archives that we have been using to locate our fractured pasts, contain the logics of a Western colonial positivist knowledge; they are "a force field that ... pulls on some 'social facts' and converts them into qualified knowledge, that attends to some ways of knowing while repelling and refusing others" (Stoler 22). The key tenets of this way of knowing are universalism, reason applied to evidence, and a teleological approach to history and civilisation (Richards 4). Its conception of history and civilisation presupposes a linear approach to time which understands civilisation to be progressing towards betterment: "the archive offers the precondition for something like history to exist, since only when the archive already exists can the comparison of the new with the old, which produces history as such, be executed" (Groys 180). So, as the archive reproduces a way of knowing that understands time in a particular way, we sought out 
strategies that would reckon with linear time, in order to explore "the multiple times of cultures and civilizations upon which Western Civilization imposes its conceptualization of time" (Mignolo qtd. in Hoffman).

\section{Queering Time via Autoethnography and Hiraeth}

In an effort to establish the different strategies that we could stake our work to, we explored several theoretical frameworks. We will trace, here, the line of enquiry that led us to unify around the methodological approach of queering time. First, the concept of hiraeth. Hiraeth is a Welsh word for which there is no English translation. It speaks of a longing or nostalgia for a home that you cannot return to because it no longer exists or never existed. Illustrator John Howe describes it as "nostalgia for what was or should have been" (emphasis in the original).

I (Onyeka Igwe) find it hard to settle on "home", settle on its definition or what it could mean to me. For many, home is a fixed point, whether it is a place or a feeling, an identity or a geography that can be returned to literally or conjured in the imaginary. Home is a centre, is the groundwork and foundation from which context and identity flow. But for me, home is on the tip of the tongue, perpetually just out of reach. Home will not be, it will not settle into a tangible form. In the words of the poem "Diaspora Blues",

So, here you are, too foreign for home, too foreign for here.

Never enough for both. (Umebinyuo 12)

Our blackness is scored by a loss, a loss of home ancestrally realised and presently felt, doubly in its absence in the historical record and the institutional archive. In Critique of Black Reason, Achille Mbembe states:

We can therefore say of the invocation of race that it is born from a feeling of loss, from the idea that the community has suffered a separation, that it is threatened with extermination, and that it must at all costs be rebuilt by reconstituting a thread of continuity beyond time, space, and dislocation. (34)

Hiraeth therefore can be understood as the condition of black diaspora, the violent removal from the land you are indigenous to, be it through economic migration or the imperialism of chattel slavery. Dylan T. Miner talks about indigeneity being centred on the connection of a people to the land-a direct and tangible relationship with land. Lacking a conception of home, the feeling of hiraeth resides in a space that has to be filled, a space that is constantly up for grabs, that is moveable. It is not as solid as land, it's much more amorphous. The absence of indigeneity, and the reality of that absence allows for something moveable that is constructed, always being produced and imagined because it's not actually there. It can't be, because it is not fixed by land.

We became drawn to hiraeth as a way of describing our shared practices because of its relation to the black diasporic condition. It can be considered as grounding for a pursuit that is realised through artistic practice as "a pouring forth, a holding or spreading out, or a running over that never runs out and is never over; a disbursal more than a dispersal; a funding that is not so much founding as continual finding of that which is never lost in being lost" (Moten, Blur xi). It's liminal, in a perpetual approaching that never reaches a final destination. 
Christina Sharpe gives us language to describe Black life in the aftermath of slavery: the wake. The wake serves as a symbol for the wake of a ship, a funeral of a loved one, or to "stay woke". In her book In the Wake: On Blackness and Being, Sharpe argues: "In the wake, the past that is not past reappears, always, to rupture the present" (9). Here, existing "in the wake" feels akin to the experience of hiraeth. While reading her book, I (JD Stokely) couldn't help but make connections to not only the wake of a slave ship, but the wake of Windrush, or a boat like it, that carried my grandfather and others to England and left families like mine in their trail. To exist in the wake is to exist in an inherently queer time, as Blackness is both stuck in the past, and always rupturing, challenging, queering the present: "Black life in and out of the 'New World' is always queered" (Sharpe 32).

Further, Howe also describes hiraeth as "a longing to be where your spirit lives". In this way, hiraeth can also be described as a haunting. In A Glossary of Haunting, Eve Tuck and C. Ree describe haunting as "the relentless remembering and reminding that will not be appeased by settler society's assurances of innocence and reconciliation" (642). This understanding of hiraeth allowed us to think of the persistent presence of our black ancestors in the archive as a form or haunting. Haunting presupposes that the past and present are not sequential, instead the past bleeds and stains the present. This relationship to time was one that we sought to reaffirm in our use of archival material.

Another concept that our work touched upon was authoethnography. Autoethnography is defined by Mary Louise Pratt as:

a text in which people undertake to describe themselves in ways that engage with representations others have made of them. Thus, if ethnographic texts are those in which European, metropolitan subjects represent to themselves their others (usually their conquered others), autoethnographic texts are representations that the so-defined others construct in response to or in dialogue with those texts. Rather they involve a selective collaboration with and appropriation of idioms of the metropolis or the conqueror. (35)

Our practices can be considered through this lens as we have both used aspects of our biography in concert with the archival and ethnographic texts that were the inspiration for We Need New Names and Reparations. The personal or familial are in dialogue with the official records of the past. In this way autoethnography appeared to be an appropriate way through or negotiation.

Both of us kept coming up against absences in our work-absences that were a result of the archive or were amplified by it. In this way, the archive became both the problem and the solution. In Disidentifications, José Esteban Muñoz explores the work of queer and trans artists of colour who found creative ways of performing their relationship to their autobiographical stories:

The queer trend that I am identifying is in many ways an effort to reclaim the past and put it in direct relationship with the present. Autoethnography is not interested in searching for some lost and essential experience, because it understands the relationship that subjects have with their own pasts as complicated yet necessary fictions. (83)

Our experience of hiraeth was not just for our respective "homelands", but a longing for a recognition of a past that could no longer exist, or never existed. Because we could not find our pasts in the archive, or because much of our pasts had been erased, these histories themselves 
became "complicated yet necessary fictions" (Muñoz 83). "Erasure concocts ghosts" (Tuck and Ree 643). But our attempts to fill the gaps were not straightforward as they weren't literal or factual, instead we "reclaim our pasts" by fictionalising those gaps and absences. To be Black and Queer to the archive means to have a refutable past. In this way, to exploit and "reclaim" these pasts mean to disidentify with them, to transform the past into a contentious space, and therefore queer our understanding of linear time.

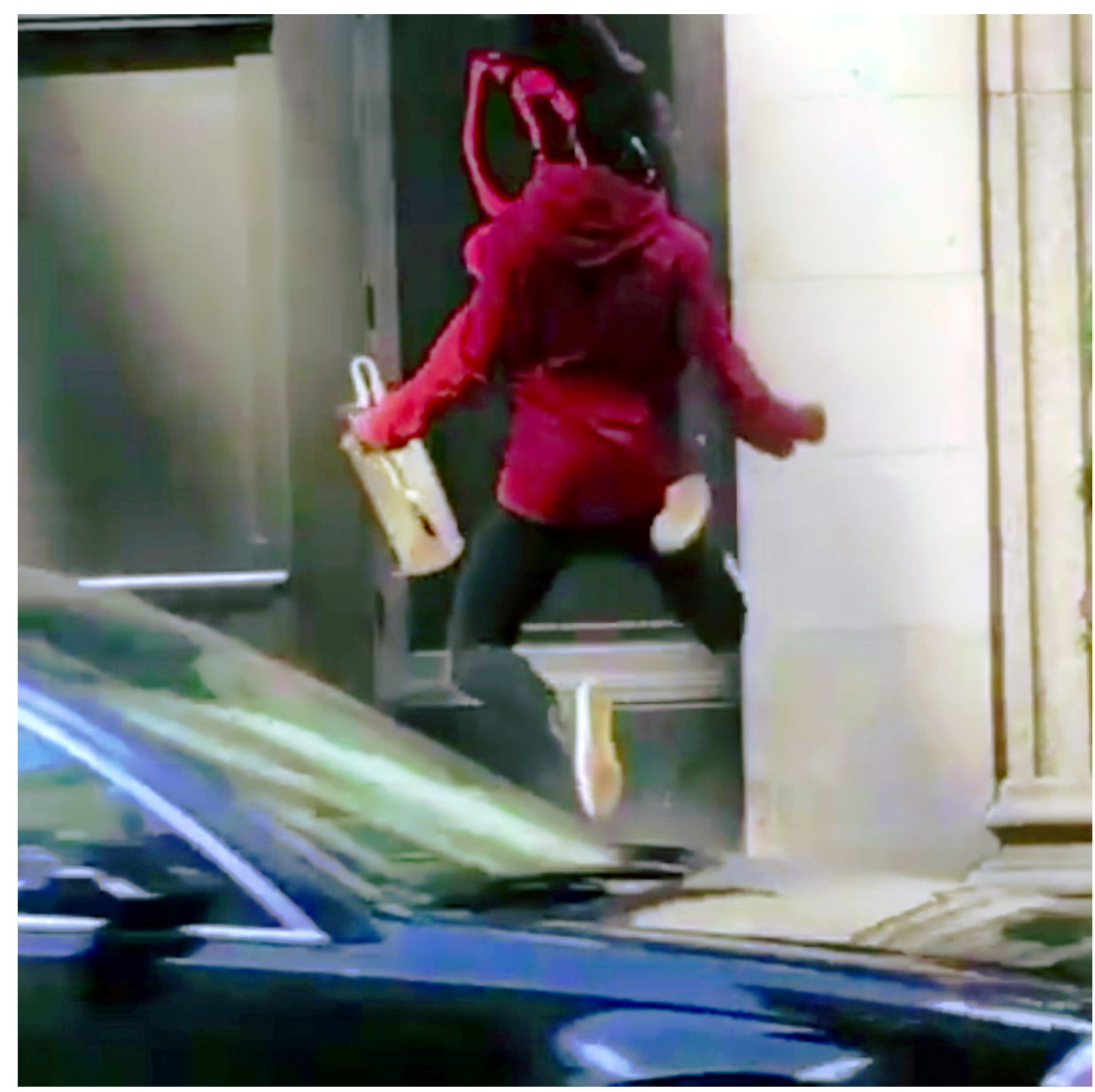

Figure 3: Thru It All - \#VoguetoGetFree by NIC Kay (2017). Screenshot.

This queering of time is present in other QTIPOC artists work. Repetition, glitching, and a breaking down of time can be a way to challenge the linearity of time. It is like pressing a reset button. Performance and video artist NIC Kay has one video called Thru It All - \#VoguetoGetFree (2017). The video follows Treyonce Julia Carter, a Black dancer, as they vogue down a busy city street, scored by Erykah Badu's cover of Wintertime's "Thru It All”. As Treyonce dances down the street, spinning, death dropping, queering this public space with their unapologetic Blackness and gender nonconformity, the video begins to warp and glitch. Where it once looks like Treyonce is falling, they now look like they are flying, or levitating (Fig. 3). On 13 October 2017 at the Queer of Color Performance and Critique Symposium at Tufts University, NIC Kay described this work in particular as a "radical black seizure"-it is another example of a Queer black subject grabbing hold of time and space. Through rupture and repetition, Kay explores "blackness as 
a/temporal, in and out of place and time putting pressure on meaning and that against which meaning is made" (Sharpe 76). The video reverses the erasure of this Black queer person, by forcing their surroundings to match their Black queer time.

Visual artist Adam Saad made a video piece that speaks to both moments and repetition. He compiled all the times that Mariah Carey says the word "moment" from YouTube videos and attributes "moments" to Carey's own queering of time (Maria). She understands time through a series of moments instead of a linear trajectory - from and to. Moments from past, present and the future can be clustered together. Time-based media uses various techniques to exploit other conceptualisations of time.

Black queer artists carving space for themselves in the archive is nothing new. Cheryl Dunye's The Watermelon Woman (1996) is a prominent example of a "complicated but necessary fiction" (Muñoz 83). In the film, young Black lesbian filmmaker Dunye searches the archives for information on Fae Richards, a Black lesbian actress who often starred in black-and-white plantation films as "the Watermelon Woman". After unsuccessful searches in film archives, university archives, and even a parody representation of the Lesbian Herstory Archives in New York City, Dunye tracks down Richards's partner, who helps her piece together the story of Fae's life. The movie ends with photos and video clips of Fae and her partner as Dunye reads a short biography of Richards's life. And then the movie shows a black screen with white text that reads: "Sometimes you have to create your own history. The Watermelon Woman is fiction." The Watermelon Woman is a critique of both history and institutional archives, and the ways that the archives abandon Black queer subjects. It wasn't until she went back to her community that she became able to uncover the story of this Queer Black woman. But Dunye also creates a history as a way to shed light on all of the ancestors - family or otherwise - that have been lost in the archive, or intentionally forgotten. In many ways, The Watermelon Woman is creating something that should be there anyway. Fae Richards would have been real; this person would have been there. Simultaneously, revealing the construction - the nature of archives:

"My archive is a dehiscence at the heart of the archive and on its edge - a disorder, an appeal" (Moten, Black Optimism 11)

As discussed earlier, the archive is populated with untruths which archivisation converts into the way in which we know peoples, cultures, concepts, things. If that is the nature of the archive, how can that be employed to heed Moten's call and make a dehiscence, a wound that ruptures? Can we imagine not only inserting fictions and untruths into the archive that operate to queer time and reveal the fictive foundations of the archive, but that also spread and spill in a way that infects everything the archive contains and transforms the way in which knowledge is produced? This question has become a driving pursuit in our practices.

\section{Conversation \#2}

STOKELY: It has been four years since we have begun this journey. Have you revisited We Need New Names, where are you now with your practice, and now what is the work?

ONYEKA: I saw We Need New Names for the first time in a long time, and I thought, "Whose voice is that? I am not that anymore." Not only are there multiple times and multiple ideas of what 
an archive can be in that piece, there are multiple versions of myself. There are lots of different versions of me in there, and they are kind of me and kind of not me and they can never possibly be me.

It makes me think of multiplicity, allowing for many things to exist at once alongside each other. And if that includes fictions then it allows for a scarring across the archive that can rupture and infect everything in it. The fictions attain the same value or worth as the "truths". They can become of the same worth as what is always there. That was a conceit of We Need New Names. I used different ethnographic material, some real and some imagined, to explore the funeral customs of Igbo people in Southeastern Nigeria with my grandmother's funeral as the focal case study. Including the imagined and fictive amongst the "true" ethnographic is the active archivisation of the impossible and untranslatable. Going back to Moten and his resolution to try, trying for me means not being definite but instead to think in as many ways as possible. So, for my practice it is about having as many times as possible, as many selves as possible, as many worlds as possible and not creating binaries or hierarchies. That is queerness, for me. There is not a solution or an end because it is not linear, it is not going somewhere. It is, instead, a tangle, all these things at once, because we exist in this space that is not settled. It is not definitive, it does not have land in which to tether us to. In and of itself it has to be that way because if you exist in this liminal space that's hiraeth, how can it not be multiple? How could it possibly be a fixed point in time?

STOKELY: I have been tracking my relationship to stuckness in my practice - that kind of refusal to end that has always been present in the work that I do. The first play I wrote, The (Sexual) Liberation of Mammy (2011), was very inspired by The Watermelon Woman. In the play, a black lesbian named Adanne is haunted by a mammy statue and other Black memorabilia she collects. The weight of the past coupled with her racially tumultuous relationship eventually cause her to have a breakdown. Her white lover Claire promises to erase the history of colonialism for her, but Claire's speech is interrupted by the Mammy statue who chastises the audience by declaring, "This isn't over... We are the ghosts that haunt the American conscience." In Reparations, the performance ends with me "forgetting" my lines, and walking out of the room, abandoning the audience.

How can you perform the gaps, or how are the gaps in and of themselves performative? Which is what Muñoz is saying too, that recognition. This dismissal of searching for something that has been lost felt to me like settling for what I had. Instead of looking at it like an advantage, I was looking at it like a disadvantage. This journey has brought me to a dead end, and therefore, I must stop or leave or feel frustrated, or lean in, but actually it turned into this playful performative space, which is what allows me to queer time.

ONYEKA: I am working on a new film. I was thinking through the archive as a visual trauma, and the ways in which it can be unmoved from that state. A traumatic visual memory. How can that be distorted or changed? How can that be displayed in the creation of a new visual reality? There is the question: can these images be unfixed from their original intention, from their meanings in the way in which they are produced? I am always thinking of what can be done to achieve it. Is it messing with time? Is it putting other imagery next to it? Is it narrative, using voice? I just set myself a challenge of, what if there are no factors apart from the image? What if all I have is the image, and what ways can I try and destabilise its colonial contexts? I have been exporting video frames from old archival film and using photoshop to remove their faces. There is a lot of work I have seen that involves artists not showing people's faces as an act of care, for example Belinda 
Kazeem-Kamiński film Unearthing. In Conversation (2017). I am strangely compelled by an image I used in Specialised Technique (2018), but at the same time, is that not the ultimate disembodiment, or depersonalisation (Fig. 4)? Is it completely removing someone's personhood from something?

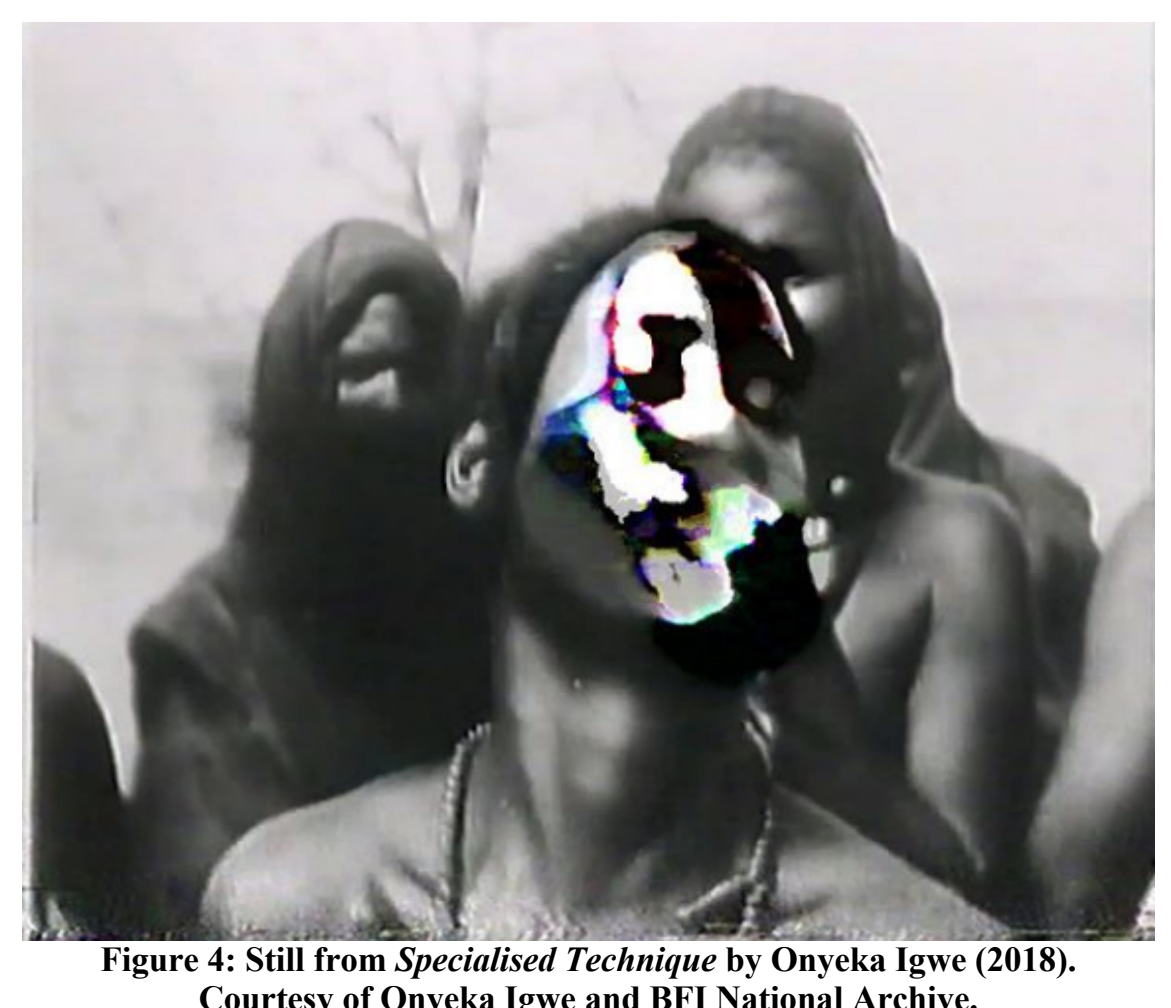

When I made We Need New Names, it was about putting different archival objects next to each other to create relationships and elevate the fiction to the same level as the archival material. That can be considered as an attempt at creating a "counterimage" (Campt 5). But now I am interested in working within the strictures of an archival image, with what can be done with its "material force" (Stoler 4).

STOKELY: It is not about dismissing it, is it really? It is about recognising it as its imperfect, contained with absences. It reminds me of Moten's acknowledgement of gaps. And it is not about filling the gaps, which is what I think I thought I was doing at first. I thought I was filling in the gaps of this family history, and that's why I was so tripped up, and I think that's why I am constantly tripped up in the work. It is that recognition that you can't fill up the gaps, you know. But how can you use them to your advantage?

ONYEKA: Yeah, and in your work, in the attempt to fill in the gaps, something else happened, right?

STOKELY: Yes, in attempting to fill the gaps, I began to "disidentify" with a linear concept of time. 
ONYEKA: Exactly, because when I think of the question, why the archives?, it is because of this idea that we talked about diaspora, what it is like, and where hiraeth enters. It is because in that space of not having that direct connection to the past, that direct relationship to the past became the relationship to the archive. And then you go to the archive and you're like, ugh, what is this? This is incomplete. This is not the solution. And then the attempt to address that incompleteness allows for creativity, allows for creation. If we theorise the archive as something that is connected with linear time, playing with the archive is always playing with time. And if we are saying hiraeth is linked to this timelessness and landlessness to diaspora, is it something that can be resolved? What is the resolution?

STOKELY: Maybe with the end of the world(s)? That's what I love about Afro-pessimism. It says that it is not a question of, will these systems of oppression end, or will these institutions topple; but when.

ONYEKA: Many have theorised the end of the world. In that they argue that our current world system does not allow for the humanity of black people, so in order for that to change, the end of the world needs to occur, "where The Thing resists dissolving any attempt to reduce what existsanyone and everything - to the register of the object, the other, and the commodity" (Silva 91).

STOKELY: We began this journey in an attempt to find ourselves and our pasts within the archive. Instead, we found gaps. These gaps became a rich space for exploration, play and performativity in our time-based practices. These gaps also became a place to queer time.

Blackness is always already an embodiment of queer time, because it is always at once a past, present, and future space. In Map to the Door of No Return: Notes to Belonging, Dionne Brand writes:

Black experience in any modern city or town in the Americas is a haunting. One enters a room and history follows; one enters a room and history precedes. History is already seated in the chair in the empty room when one arrives. Where one stands in a society seems always related to this historical experience. (25)

We would also argue that it is always an imagined one.

\footnotetext{
Note

${ }^{1}$ We understand queer through Judith Butler's conception of a performativity that operates against the "ordinary and academic discourses on sexuality", gender and sex (xx). Queer theory dynamised "queer" into a verb that is bound up in the agency of self-construction. So, queering is about the active, defiant and political disrespect of certain existing norms, rules, and binaries. Their institution or their solidity is challenged, and so, up for grabs.
} 


\section{References}

Badu, Erykah. "I Been Goin Thru it All.” 21 Apr. 2016, soundcloud.com/erykah-she-ill-badu/ebadu-i-been-goin-thru-it-all-420-mix. Accessed 20 Oct 2018.

Bradley, Rizvana. "Black Cinematic Gesture and the Aesthetics of Contagion." TDR: The Drama Review, vol. 62, no. 1, Feb. 2018, pp. 14-30.

Brand, Dionne. A Map to the Door of No Return: Notes to Belonging. Vintage Books Canada, 2002.

British Pathé. Royal Tour - Nigeria Dances, 1956, www.britishpathe.com/video/royal-tournigeria-dances. Accessed 9 Oct. 2018.

Butler, Judith. Gender Trouble: Feminism and the Subversion of Identity. Routledge, 1999.

Campt, Tina. Image Matters: Archive, Photography, and the African Diaspora in Europe. Duke UP, 2012.

"Colonial Film Unit." Colonial Film: Moving Images of the British Empire. www.colonialfilm. org.uk/production-company/colonial-film-unit. Accessed 6 Dec. 2017.

Derrida, Jacques. Archive Fever: A Freudian Impression. Translated by Eric Prenowitz, U of Chicago P, 1996.

Dunye, Cheryl, director. The Watermelon Woman. Dancing Girl, 1997.

Foucault, Michel. Archaeology of Knowledge. Translated by A.M. Sheridan Smith, Routledge, 2002.

"Get Well Soon: On Class and Disability." Panel, El Amor en Tiempos de Trump: Queer of Color Criticism and Performance Conference. Tufts University, Medford, MA, 13 Oct. 2017, www.youtube.com/watch? $\mathrm{v}=\mathrm{mZT} 014 \mathrm{gNc5Q}$. Accessed 9 Oct. 2018.

Graham, Martha. Blood Memory. First edition, Doubleday, 1991.

Groys, Boris. "What Carries the Archive - and for How Long?" Translated by Stephen Kovas, Information Is Alive: Art And Theory on Archiving and Retrieving Data, edited by Joke Brouwer et al., V2/NAi Publishers, 2003, pp. 178-93.

Hartman, Saidiya. "Venus in Two Acts." Small Axe, vol. 12, no. 2, July 2008, pp. 1-14.

Harney, Stefano, and Fred Moten. The Undercommons: Fugitive Planning \& Black Study. Minor Compositions, 2013.

Hoffman, Alvina. Interview - Walter D. Mignolo. E-International Relations, 21 Jan. 2017, www.eir.info/2017/06/01/interview-walter-d-mignolo. Accessed 9 Oct. 2018. 
Howe, John. "Hiraeth, or Hekate as the Muse." john-howe.com, 14 Sept. 2017, www.johnhowe.com/blog/2017/09/14/hiraeth-or-hekate-as-the-muse. Accessed 9 Oct. 2018.

Igwe, Onyeka, director. We Need New Names. 2015.

---. Her Name in My Mouth. 2017.

---. Specialised Technique. 2018.

Kay, NIC, director. Thru it All - \#VoguetoGetFree. 2017, vimeo.com/216071742. Accessed 9 Oct. 2018.

Kazeem-Kamiński, Belinda, director. Unearthing. In Conversation. 2017.

Kurtz, Matthew. "A Postcolonial Archive? On the Paradox of Practice in a Northwest Alaska Project." Archivaria: The Journal of the Association of Canadian Archivists, vol. 61, 2006, pp. 63-90.

Lightman, Alan P. Einstein's Dreams. A. A. Knopf Canada, 1993.

Mackindral, Maya. "Diverus: The Past, Present, and Future of "Diversity Work." MICE Magazine, no. 1, 11 Apr. 2016, micemagazine.ca/issue-one/diverus. Accessed 9 Oct. 2018.

Maria, Pia. "Anticipating Asymmetric Grief." Atractivoquenobello, 14 July 2015, www.aqnb.com/ 2015/07/14/anticipating-asymmetric-grief. Accessed 9 Oct 2018.

Mbembe, Achille. Critique of Black Reason. Translated by Laurent Dubois, Duke UP, 2017.

Miner, Dylan T. "Giiwekii // They Return Home to the Land: Indigenous Art as Research in an Age of Ongoing Colonialism.” Keynote, PARSE Conference, University of Gothenburg, 26 Nov. 2017.

Moten, Fred. Black Optimism/Black Operation. unpublished, 2007.

---. Black and Blur. Duke UP, 2017.

Muñoz, José Esteban. Disidentifications: Queers of Color and the Performance of Politics, U of Minnesota P, 1999.

Pratt, Mary Louise. “Arts of the Contact Zone.” Profession, 1991, pp. 33-40.

Rankine, Claudia. Citizen: An American Lyric. Graywolf Press, 2014.

Richards, Thomas. The Imperial Archive: Knowledge and the Fantasy of Empire. Verso, 1993.

Sharpe, Christina. In the Wake: On Blackness and Being. Duke UP, 2016. 
Silva, Denise Ferreira da. "Toward a Black Feminist Poethics: The Quest(ion) of Blackness Toward the End of the World." The Black Scholar, vol. 44, no. 2, 2014, pp. 81-97.

Stokely, JD, director. Reparations. 2014.

---. The (Sexual) Liberation of Mammy. 2011.

Stoler, Ann Laura. Along the Archival Grain: Epistemic Anxieties and Colonial Common Sense. Princeton UP, 2009.

Tuck, Eve, and C. Ree. “A Glossary of Haunting." Handbook of Autoethnography, edited by Stacy Holman Jones, Tony E. Adams, and Carolyn Ellis, Routledge Handbooks Online, 2013, DOI: $10.4324 / 9781315427812 . \operatorname{ch} 33$.

Umebinyuo, Ijeoma. Questions for Ada. CreativeSpace Independent Publishing Platform, 2015.

\section{Suggested Citation}

Igwe, Onyeka, and JD Stokely. "Hiraeth, or Queering Time in Archives Otherwise." Alphaville: Journal of Film and Screen Media, no. 16, Winter 2018, pp. 9-23. www. alphavillejournal.com/Issue16/ArticleIgweStokely.pdf.

Onyeka Igwe is an artist filmmaker and $\mathrm{AHRC}$ funded $\mathrm{PhD}$ researcher at University of the Arts London. She has been published in MIRAJ and NON Quarterly: Volume 1. Her video works have shown at the Institute of Contemporary Arts, London; Trinity Square Video, Toronto; The Showroom, London; articule, Montreal; and at the London, Rotterdam International, Edinburgh Artist Moving Image, and Hamburg film festivals. Onyeka was awarded the 2018 British Assoc. of Film \& TV Studies, Best Practice Research Portfolio: Experimental, and is nominated for the 2018 Arts and Humanities Research Council, Research in Film Awards.

JD Stokely is a trickster-in-training hailing from Philly-by-way-of-Boston. They create and curate lectures, workshops, and performances around Queerness, nostalgia, the Black body, and home. Stokely is an associate producer of HowlRound Theatre Commons and the director of True Colors, the Theatre Offensive's LGBTQ+ youth troupe. Stokely is a cofounder of Unbound Bodies, a multidisciplinary arts lab for QTBIPOC creatives in the Greater Boston area. Stokely is also a founding member of SUPER|object, a Queer curatorial collective that serves as an arts incubator for emerging artists, and A Collective Apparition, a group of LGBTQ Black artists whose work is "rooted in the past, but poised on the crux of the present \& future." Stokely received an MA in Advanced Theatre Practice from Royal Central School of Speech \& Drama in 2014, and a BA from Hampshire College in 2011. 